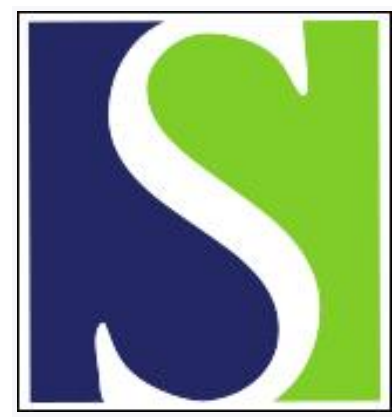

Scand J Work Environ Health 2014;40(3):278-286

https://doi.org/10.5271/sjweh.3415

Published online: 09 Jan 2014, Issue date: 01 May 2014

Predictors of sickness absence related to musculoskeletal pain: a two-year follow-up study of workers in municipal kitchens

by Haukka E, Kaila-Kangas L, Luukkonen R, Takala E-P, Viikari-Juntura $E$, Leino-Arjas P

We identified three distinct trajectories of sickness absence (SA) due to musculoskeletal pain among female kitchen workers during two years. Depressive symptoms, musculoskeletal diseases, and multisite pain predicted belonging to a trajectory of high and increasing SA, while multisite pain, smoking, and overweight or obesity predicted belonging to a trajectory of intermediate occurrence of SA.

Affiliation: Finnish Institute of Occupational Health, Topeliuksenkatu 41 a A, FI-00250, Helsinki, Finland. Eija.Haukka@ttl.fi

Refers to the following texts of the Journal: 2009;35(5):325-333 2010;36(1):1-2 2010;36(1):34-41

Key terms: depression; kitchen; kitchen worker; lifestyle; longitudinal; musculoskeletal disease; musculoskeletal disorder; musculoskeletal pain; predictor; repeated measurement; sickness absence; trajectory; widespread pain

This article in PubMed: www.ncbi.nlm.nih.gov/pubmed/24407882

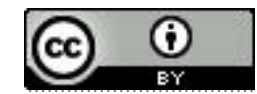




\title{
Predictors of sickness absence related to musculoskeletal pain: a two-year follow-up study of workers in municipal kitchens
}

\author{
By Eija Haukka, PhD,1, 2 Leena Kaila-Kangas, PhD,1,2 Ritva Luukkonen, PhD, ${ }^{3}$ Esa-Pekka Takala, PhD,1,2 \\ Eira Viikari-Juntura, PhD, ${ }^{2}$ Päivi Leino-Arjas, PhD ${ }^{1,2}$
}

\begin{abstract}
Haukka E, Kaila-Kangas L, Luukkonen R, Takala E-P, Viikari-Juntura E, Leino-Arjas P. Predictors of sickness absence related to musculoskeletal pain: a two-year follow-up study of workers in municipal kitchens. Scand $J$ Work Environ Health. 2014;40(3):278-286. doi:10.5271/sjweh.3415
\end{abstract}

\begin{abstract}
Objective We studied predictors of sickness absences (SA) due to musculoskeletal pain over two years among 386 municipal female kitchen workers.

Methods Pain and SA periods (no/yes) due to pain in seven sites during the past three months were assessed at 3 -month intervals over two years by questionnaire. Age, musculoskeletal pain, multisite pain (pain in $\geq 3$ sites), musculoskeletal and other somatic diseases, depressive symptoms, physical and psychosocial workload, body mass index, smoking, and leisure-time physical activity (LTPA) at baseline were considered as predictors. Trajectory analysis and multinomial logistic regression were used.
\end{abstract}

Results Three trajectories of SA emerged, labelled as "none" ( $41 \%$ of the subjects), "intermediate" (48\%), and "high" (11\%). With the "none" trajectory (no SA) as reference, pain in all musculoskeletal sites excepting the low back predicted belonging to the "intermediate" [odds ratio (OR) 1.82-2.48] or "high" (OR 2.56-3.74) trajectory adjusted for age; multisite pain predicted membership of the "intermediate" [OR 2.15, 95\% confidence interval (95\% CI) 1.38-3.34] or "high" (OR 4.66, 95\% CI 2.10-10.3) trajectories. In a mutually adjusted final model, smoking (OR 2.12, 95\% CI 1.22-3.69), multisite pain (OR 1.87, 95\% CI 1.15-3.02), and overweight/obesity (OR 1.71, 95\% CI 1.08-2.72) predicted belonging to the "intermediate" trajectory, while depressive symptoms (OR 3.57, 95\% CI 1.57-8.10), musculoskeletal diseases (OR 3.18, 95\% CI 1.37-7.37), and multisite pain (OR $2.72,95 \%$ CI 1.15-6.40) were associated with the "high" trajectory.

Conclusion Along with the number of pain sites and musculoskeletal diseases, attention to depressive symptoms, smoking, and overweight/obesity is needed to tackle SA related to musculoskeletal pain.

Key terms depression; kitchen worker; lifestyle; longitudinal; musculoskeletal disease; musculoskeletal disorder; repeated measurement; trajectory; widespread pain.

Possibilities to control long-term and repeated sickness absence (SA) are currently among the top policy priorities in many European countries due to the various costs involved both to society and the individual (1). The importance of SA is emphasized as it has been found to be a precursor to permanent work disability $(2,3)$.

Musculoskeletal $(4,5)$ and mental health problems, especially depression $(3,6)$ are the dominant medical causes of SA. With regard to musculoskeletal disorders, neck pain and low-back pain have received most attention in this respect $(5,7-8)$. While a range of other factors, such as female gender (9), increasing age, high physical workload (9-11), poor psychosocial working conditions, obesity, smoking (9-11), and being physically inactive during leisure-time (12), have been implicated as risk factors for SA in general, little is known about their importance regarding SA due to musculoskeletal pain specifically.

Current epidemiological evidence suggests that musculoskeletal pain at several sites is more common and may be more disabling than single-site pain (13). The importance of examining factors related to SA over time

\footnotetext{
${ }^{1}$ Centre of Expertise for Health and Work Ability, Finnish Institute of Occupational Health, Topeliuksenkatu 41 a A, FI-00250, Helsinki, Finland.

2 Disability Prevention Centre, Finnish Institute of Occupational Health, Topeliuksenkatu 41 a A, FI-00250, Helsinki, Finland.

${ }^{3}$ Statistics and Health Economics, Finnish Institute of Occupational Health, Topeliuksenkatu 41 a A, FI-00250, Helsinki, Finland.

Correspondence to: Eija Haukka, Finnish Institute of Occupational Health, Topeliuksenkatu 41 a A, FI-00250, Helsinki, Finland. [E-mail: Eija.Haukka@ttl.fi]
} 
has also been underlined (14). In the Finnish public sector, kitchen workers are among the three occupations with the highest rates of SA (15). We have previously found that multisite pain among female municipal kitchen workers is common (16). In the current work among this occupational group, our aim was to study to what extent multisite pain and musculoskeletal diseases, as well as other somatic diseases, depressive symptoms, physical and psychosocial workload, and health-related lifestyle factors are predictive of the course of SA related to musculoskeletal pain during a two-year follow-up.

\section{Methods}

\section{Study setting and participants}

This two year longitudinal study was based on data derived from a cluster randomized controlled trial which the Finnish Institute of Occupational Health conducted during 2002-2005 in four large cities in Finland aimed at assessing the efficacy of a participatory ergonomics intervention in preventing musculoskeletal disorders among 504 workers of 119 municipal kitchens of schools, nurseries, nursing homes, or geriatric service centers. No systematic differences between the intervention and control groups were found in musculoskeletal disorders or SA due to musculoskeletal pain during the intervention or during the one-year follow-up period (17). Thus, we pooled the data for the analyses in the current work. Due to the limited number of men $(\mathrm{N}=17)$, the analyses were carried out among women only $(\mathrm{N}=487)$. The final sample comprised 386 women, based on the inclusion criterion of trajectory analysis (see below).

\section{Procedure}

Data were collected by questionnaire repeatedly at nine time points: baseline (0), and thereafter at $3,6,9,12$, $15,18,21$, and 24 months. The researchers distributed the questionnaires at workplaces. The questionnaires were mailed to those on vacation or sick leave with the instruction to respond within one week after returning to work. Non-responders were reminded by phone after two weeks. The response rates at each time point exceeded $90 \%$.

\section{Sickness absence due to musculoskeletal pain}

The subjects were inquired at each time point about the occurrence of SA during the past three months by seven questions of the format: "Have you been on sick leave due to [body area] pain during the past three months (no/ yes)?" The sites inquired about were the neck, shoulders, forearms/hands, the low back, hips, knees, and ankles/ feet. The repeated measurements enabled us to study the course of SA over time by trajectory analysis.

\section{Possible predictors}

Musculoskeletal pain. Pain in the above-mentioned seven anatomical sites was measured by the following questions modified from the validated questionnaire (18): "Have you had [body area] pain during the past three months (no/yes)?" A mannequin illustrated the body sites. Pain in the left and right shoulder, and similarly pain in the forearm and hand, was combined for analysis (if one of the answers was "no" and the other missing, the response was defined as missing; if either response was "yes", the combined variable was defined as "yes").

A sum index $(0=$ no pain, $7=$ pain in 7 sites $)$ was calculated and used both as a continuous variable and dichotomized with the median as cut-off point to $0-2$ pain sites (no multisite pain) and $\geq 3$ pain sites (multisite pain)

Musculoskeletal and other somatic diseases. The subjects were posed the question: "Do you have any of the following chronic diseases for which you have needed medical care during the past 12 months (no/yes)"? If the response to any of the items "inflammatory articular disease (eg, inflammatory arthritis or ankylosing spondylitis), arthrosis, or upper/lower limb injury due to an accident" was yes, the subject was considered to have a musculoskeletal disease. Similarly, having another somatic disease was defined as at least one positive response to the other items in the list (including diseases of the cardiovascular, respiratory, gastrointestinal, neurological, genitourinary, or metabolic/endocrine systems, skin diseases, and hematological diseases).

Depressive symptoms. These were assessed by a modified version of the validated Depression Scale (DEPS) $(19,20)$ including 10 items concerning one's mood during the past month (suffered from insomnia, felt blue, felt everything was an effort, felt low in energy or slowed down, felt lonely, felt hopeless about the future, not having any fun in life, had feelings of worthlessness, felt all pleasure and joy has gone from life, felt unable to shake off the blues even with help from family and friends). Each item had originally five categories $(1=$ never, $2=$ seldom, $3=$ sometimes, $4=$ quite often, $5=$ always), each of which was dichotomized to represent a depressive symptom (no $=1-2$, yes $=3-5)$. A sum score (Cronbach's $\alpha=0.79$ ) was calculated (scale $0-10)$ and, with the median as cut-off point, depressive symptoms were dichotomized as no ( $0-1$ symptoms) and yes ( $\geq 2$ symptoms). 
Physical workload. The workers were asked to rate the physical strenuousness of seven main work tasks during the previous week (preparation, cooking and baking, distribution and serving of food, packing food to be delivered to clients, dishwashing, cleaning and maintenance of room and equipment, and receiving and storing of raw material). The scale ranged from 1 (not at all strenuous) to 7 (very strenuous). The mean of the seven work tasks was used to describe overall physical workload (21). Using the median as cut-off point, physical workload was dichotomized to low $(<3.7)$ and high $(\geq 3.7)$.

Psychosocial workload. We assessed this predictor using eight questions from a validated questionnaire (22): job control ("At work, can you influence matters concerning you?"), skills discretion ("Can you use your knowledge and skills in your work?"), and supervisor support ("Does your supervisor provide support and help when needed"?) were classified similarly (1=very much, ..., 5=not at all). The remaining items included: job satisfaction ("How satisfied are you with your present work?" $1=$ very satisfied, ..., $5=$ very dissatisfied); co-worker relationships ("How do workmates get along at your workplace?" $1=$ very well, ..., 5=badly); hurry at work ("Do you have to hurry to get your work done?" $1=$ never, ..., $5=$ constantly); mental strenuousness of work ("Is your work mentally strenuous?" $1=$ not at all, ..., $5=$ very strenuous); and difficult work phases ("Does your work have phases that are too difficult?" $1=$ never, ..., $5=$ constantly). A sum score was constructed (Cronbach's $\alpha=0.76$ ) (21) and, with the median as cut-off point, dichotomized as low $(<19)$ and high $(\geq 19)$ psychosocial workload.

Body mass index (BMI). Calculated based on selfreported height and weight $\left(\mathrm{kg} / \mathrm{m}^{2}\right)$, BMI was classified as normal $(<25)$ or overweight/obesity $(\geq 25)(23)$.

Smoking. To assess whether participants were smokers (no/yes), we asked the question "Do you smoke regularly (daily/almost daily)?" (21).

Leisure-time physical activity (LTPA). We assessed LTPA by the question: "During the past 12 months, how many times a week did you exercise at $\geq 20$ minutes per session, to the extent to cause perspiration?" (not at all, $<1$ /week, 1, 2-3, 4-5, or 6-7 times/week) (21). The exercise frequency was dichotomized as low $(\leq 1 /$ week $)$ and high $(>1 /$ week).

Other predictors. Age (continuous), as well as study arm (intervention/control group), and organizational reforms (no/yes) were considered in all analyses because the core study on which the current analyses were based had a randomized design (17), and in two of the participating cities, reorganization of foodservice was implemented during the study period (24).

\section{Statistical analysis}

Descriptive statistics were used to present the baseline characteristics of the study population. To describe the course of SA over two years, we used a semiparametric group-based modeling strategy by PROC TRAJ in SAS version 9.1 (SAS Institute, Cary, NC, USA). This method was developed for analyzing longitudinal data, changes over time, and identifying distinct latent groups of subjects who tend to have a similar profile over time (trajectories). The Bayesian information criterion (BIC) is used as the basis for selecting the optimal model, number of trajectories and their shape. Based on posterior probability (ideally near 1 , at least 0.70 ), the subjects are assigned to the trajectory that best matches their behavior. In the analysis, all available data points during a given period are used. Trajectory analysis accommodates missing data, but for individuals with very incomplete histories, exclusion from analysis is a practical necessity $(25,26)$. We set as a criterion for inclusion that data on SA due to musculoskeletal pain from $\geq 4$ of the 9 time points be available. Based on this, our final sample comprised 386 women. With binary data, the binary logit distribution was used as the underlying statistical model.

Predictors of trajectory membership were analyzed by multinomial logistic regression, with study arm (intervention/control) and organizational reforms (no/ yes) considered in all models. First, the age-adjusted effects of musculoskeletal pain at each site were analyzed separately and using the pain sum score as a continuous variable. Second, the effects of multisite pain (the dichotomized sum score) and other predictors were modelled in three steps. The factors showing an association with SA when adjusted for age were included in a multivariable model, and all variables associated with SA at this step were chosen to the final model. Odds ratios (OR) and their $95 \%$ confidence intervals $(95 \%$ CI) were calculated. The collinearity diagnostic statistics indicated no serious problem of multicollinearity between the predictors, since variance inflation factor values were low, varying from 1.04-1.30. The number of missing values in the predictors at baseline was 5.4\% at highest. The analyses were performed by using SPSS software, version 20.0 (IBM Corp, Armonk, NY, USA).

\section{Results}

The characteristics of the study material at baseline (386 female workers with an average age of 46 years) are 
Table 1. Distribution of the predictors in the total sample of female kitchen workers at baseline and by trajectories of sickness absence related to musculoskeletal pain. [BMI=body mass index; LTPA=leisure-time physical activity; SD=standard deviation.]

\begin{tabular}{|c|c|c|c|c|c|c|c|c|c|c|c|c|c|c|c|c|}
\hline \multirow[t]{3}{*}{ Predictors at baseline } & \multirow{2}{*}{\multicolumn{4}{|c|}{ Total $(\mathrm{N}=386)$}} & \multicolumn{12}{|c|}{ Sickness absence trajectories } \\
\hline & & & & & \multicolumn{4}{|c|}{$\operatorname{High}(\mathrm{N}=43)$} & \multicolumn{4}{|c|}{ Intermediate $(\mathrm{N}=185)$} & \multicolumn{4}{|c|}{ None $(\mathrm{N}=158)$} \\
\hline & $\mathrm{N}$ & $\%$ & Mean & SD & $\mathrm{N}$ & $\%$ & Mean & SD & $\mathrm{N}$ & $\%$ & Mean & SD & $\mathrm{N}$ & $\%$ & Mean & SD \\
\hline Age (years) & & & 46.0 & 8.7 & & & 46.5 & 8.4 & & & 46.0 & 8.4 & & & 45.8 & 9.1 \\
\hline Neck pain (yes) & 274 & 71.2 & & & 36 & 85.7 & & & 140 & 75.7 & & & 98 & 62.0 & & \\
\hline Shoulder pain (yes) & 131 & 34.1 & & & 19 & 44.2 & & & 76 & 41.5 & & & 36 & 22.8 & & \\
\hline Forearm/hand pain (yes) & 184 & 47.9 & & & 23 & 54.8 & & & 99 & 53.8 & & & 62 & 39.2 & & \\
\hline Low-back pain (yes) & 184 & 47.9 & & & 24 & 57.1 & & & 87 & 47.3 & & & 73 & 46.2 & & \\
\hline Hip pain (yes) & 73 & 19.0 & & & 14 & 32.6 & & & 35 & 19.0 & & & 24 & 15.3 & & \\
\hline Knee pain (yes) & 118 & 30.8 & & & 20 & 46.5 & & & 58 & 31.9 & & & 40 & 25.3 & & \\
\hline Ankle or foot pain (yes) & 113 & 29.4 & & & 13 & 30.2 & & & 68 & 37.0 & & & 32 & 20.3 & & \\
\hline Multisite pain ( $\geq 3$ pain sites, yes) & 202 & 52.3 & & & 31 & 72.1 & & & 107 & 57.8 & & & 64 & 40.5 & & \\
\hline Musculoskeletal diseases (yes) & 84 & 22.6 & & & 17 & 42.5 & & & 42 & 23.6 & & & 25 & 16.2 & & \\
\hline Other somatic diseases (yes) & 122 & 31.9 & & & 20 & 47.6 & & & 62 & 34.1 & & & 40 & 25.3 & & \\
\hline Depressive symptoms (yes) & 177 & 45.9 & & & 31 & 72.1 & & & 90 & 48.6 & & & 56 & 35.4 & & \\
\hline Physical workload (high) & 192 & 50.8 & & & 26 & 61.9 & & & 89 & 49.4 & & & 77 & 49.4 & & \\
\hline Psychosocial workload (high) & 195 & 51.3 & & & 26 & 63.4 & & & 99 & 53.8 & & & 70 & 45.2 & & \\
\hline BMI (overweight/obesity) & 178 & 47.2 & & & 23 & 56.1 & & & 93 & 51.4 & & & 62 & 40.0 & & \\
\hline Smokers & 96 & 24.9 & & & 12 & 27.9 & & & 55 & 29.9 & & & 29 & 18.4 & & \\
\hline LTPA (low ) & 146 & 38.4 & & & 21 & 50.0 & & & 68 & 37.8 & & & 57 & 36.1 & & \\
\hline
\end{tabular}

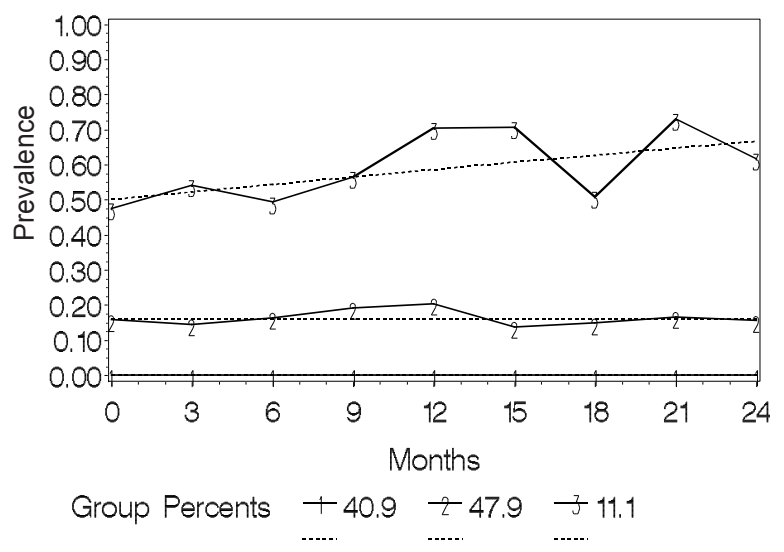

Figure 1. Trajectories of sickness absence (SA) due to musculoskeletal pain over two years among female kitchen workers $(\mathrm{N}=386) .1=$ None (no SA), 2=Intermediate (intermediate occurrence of SA), and 3=High (high and increasing occurrence of $\mathrm{SA}$ ). - Observed ---- Predicted

described in table 1. Musculoskeletal pain was highly prevalent. Only $13 \%$ of the subjects were pain-free during the past three months, $14 \%$ reported pain in 1 site, $19 \%$ in 2 sites, and $52 \%$ in $\geq 3$ of the 7 sites. The average number of pain sites was 2.8 . Neck pain was the most common with a three-month prevalence of $71 \%$, followed by pain in the forearms/hands $(48 \%)$, low back (48\%), shoulders (34\%), knees (31\%), ankles/feet (29\%), and hips (19\%). Chronic diseases were common with $23 \%$ of the women having a musculoskeletal disease and $32 \%$ some other somatic disease. Depressive symptoms during the past month were reported by $46 \%$.
Every second worker was overweight or obese and a quarter smoked regularly.

\section{Sickness absence trajectories}

In trajectory analysis, a three-group model including one trajectory with the intercept only and two with a linear shape had the best fit to the data (figure 1). The workers ( $\mathrm{N}=158,41 \%)$ assigned to trajectory 1 ("none") had no SA due to musculoskeletal pain over the follow-up. Trajectory 2 ("intermediate") consisted of 185 workers (48\%) among whom the prevalence of SA was rather stable varying from $18-29 \%$ during the follow-up. In trajectory 3 ("high"), the workers $(\mathrm{N}=43,11 \%)$ had a high and increasing prevalence of absences varying from $52-83 \%$ at different time points over the two years. The mean group membership probabilities were 0.57 [standard deviation (SD) 0.03] for the "none", 0.86 (SD 0.16 ) for the "intermediate", and 0.82 (SD 0.16 ) for the "high" trajectory.

\section{Predictors at baseline in relation to sickness absence trajectories}

With the "none" trajectory as reference, pain in the all specific sites with the exception of the low back, predicted belonging to the "intermediate" (OR 1.822.48) or "high" (OR 2.56-3.74) trajectory of SA when adjusted for age (table 2).

Using the sum score of musculoskeletal pain as a continuous variable in a multinomial regression model that adjusted for age, study arm, and organizational 
We found no previous studies on the predictors of the course of musculoskeletal pain-related SA over time. Regarding all SA, we reported recently that the number of pain sites, musculoskeletal and mental diseases, physical workload, low job control, obesity, current smoking, and sleep disorders predicted a high occurrence of long (>2 weeks) SA over a 7-year period among occupationally active Finns (11).

The need for longitudinal studies using repeated measurements (27) and examining factors in relation to persistence and changes in SA behavior over time has recently been underlined (14). Our findings on three distinct SA trajectories support the importance of uncovering underlying factors for differences in SA behavior. The trajectory group with the highest and increasing occurrence of SA was the smallest, but this seems like a challenge for healthcare professionals: $72 \%$ of these workers reported depressive symptoms and musculoskeletal pain in $\geq 3$ sites and reported also more chronic diseases compared to the workers in the other groups, $>50 \%$ were exposed to high physical and psychosocial workload, every $2^{\text {nd }}$ was overweight or obese and physically inactive during leisure-time, and roughly $1 / 3$ smoked regularly.

There is little research concerning risk factors of SA related to musculoskeletal pain in general. Studies have mostly examined SA attributed to neck and back disorders $(5,28)$. Based on their review, Kuijer et al (28) concluded that no core sets of predictors exist for SA among patients with chronic low-back pain. Hansson and Jensen (5) reviewed numerous factors in relation to SA attributed to back and neck disorders. They found consistent but limited support that heavy physical workload, low work satisfaction, specific back diagnoses, previous sick leave due to back disorders, self-reported pain, and functional impairments were associated with such SA.

In our analyses, when musculoskeletal pain sites were analyzed separately, pain in all specific anatomical sites excepting the low back predicted the course of SA. Among the kitchen workers, the predominating pain was neck not low back pain, which was likely due to the loading conditions with high demands on the upper limbs and the upper back. Each increment in the number of pain sites increased the risk of SA, and the effect of multisite pain was strong. We did not find evidence for synergism of the pain sites in relation to SA, however (data not shown).

Only a few longitudinal studies exist regarding the number of pain sites in relation to SA due to musculoskeletal pain. In spite of the differences in definitions of the determinants and the outcomes, these studies are in line with our results. Morken et al (29) found that an increase in the number of pain sites increased the risk of SA due to musculoskeletal disorders in a two-year follow-up among industrial workers. In the occupational health setting, the workers with low-back pain and concurrent other musculoskeletal complaints at another site were more likely to remain longer on a sick leave compared to those with only low back pain (30).

In cross-sectional studies the results have been inconsistent: among dentists, pain in multiple sites increased the risk of SA due to musculoskeletal pain (31), but among industrial workers the co-occurrence of neck-shoulder complaints and low-back pain was not associated with SA due to low-back pain (32).

It has been shown that musculoskeletal pain and depression often co-occur $(33,34)$ and that those with both musculoskeletal pain and depressive symptoms have a high probability of work absenteeism (35). In our sample, pain and depressive symptoms also often coexisted, particularly in the trajectory of high SA, with $71 \%$ of subjects experiencing both. No (multiplicative) interaction between multisite pain and depressive symptoms or between the number of pain sites and the number of depressive symptoms as continuous variables was found, however (data not shown). Instead, depressive symptoms, musculoskeletal diseases, and multisite pain independently predicted a high occurrence of absences, controlling for overweight/obesity and smoking. It is notable that depressive symptoms were important predictors of a high occurrence of pain-related SA, particularly as depressive symptoms may be left undetected and untreated if they are comorbid with musculoskeletal pain (33).

In the present material, high physical workload had no effect on pain-related SA. This may be due to the restricted variance in physical workload since in kitchen work physical work demands are generally high. In small work communities, like those studied here, where the work is carried out in close cooperation daily, the importance of good social relationships is emphasized with regard to well-being at work. Therefore it was unexpected that psychosocial factors at work were not more clearly associated with SA. We have found in the current material that psychosocial factors at work and multisite pain were closely connected predicting each other in time (36). This suggests that part of the negative experiences in the domain of psychosocial working conditions may be expressed as musculoskeletal pain, diminishing the discernible association of the former with SA. In our population-level study, physical workload and low job control (but neither job demands nor supervisor or coworker support) independently predicted the course of SA over time (11).

Health-related behavior seemed to be of importance, with both smoking and overweight/obesity at baseline associating with membership in the "intermediate" trajectory of SA. Although statistically non-significant, the effect sizes of these factors in the high trajectory were yet comparable to those regarding membership in the "intermediate" trajectory. The results correspond 
to those found in previous studies relative to all SA regardless of diagnosis $(10,11,37)$. Overweight and obesity, being pro-inflammatory states, may increase pain perception and its consequences for work ability.

We found no statistically significant effect of LTPA on the course of SA due to musculoskeletal pain among kitchen workers, similar to the study of all SA among occupationally active Finns (11). Previously, van Amelsvoort et al (12) observed less SA among physically active compared to inactive workers, mainly due to a decrease in absences caused by musculoskeletal disorders. The results were not adjusted (eg, for other lifestyle factors that often covary with LTPA). In our study, low physical activity increased the risk of high occurrence of SA when only age was adjusted for with a statistically non-significant OR of 1.64 .

A strength of our study was the longitudinal design with utilization of the repeated measurements at nine time points over two years in the analysis of SA trajectories. Musculoskeletal pain was measured by modified questions from the validated Nordic Musculoskeletal Questionnaire (18). A mannequin illustrated the body sites of interest. This probably enhanced the reliability of reporting, since only a verbal description might leave too large a share for individual opinion on what represents, for example, the neck, shoulder, or forearm. On the other hand, the use of a mannequin may have lowered the threshold for reporting pain leading to higher pain prevalence rates than a written question (38). The measure of musculoskeletal diseases was limited and may have produced underestimation. The assessment of depressive symptoms was based on the validated DEPS scale $(19,20)$ that has been in active clinical use for screening of primary care patients. Also psychosocial workload was assessed using questions adapted from a validated questionnaire (22). The question of physical workload and the use of seven categories were modified specifically for kitchen work, since no suitable published methods were available. Previous studies have suggested that the minimum number of categories should be between five to seven, and that up to seven the reliability of the measure increases (39). A self-administered questionnaire is still the most widely used method for assessing physical workload (40).

Our study had some limitations. We focused on a single occupational group and the sample consisted exclusively of women restricting the generalizability of the results. The relatively small sample size increased imprecision of the risk estimates. All our measures were based on self-reports, both due to the scarcity of more objective methods practicable in epidemiological studies and financial considerations. Register-based SA data were not available, but the use of self-reports enabled us to obtain information on (self-assessed) causes of even short spells, usually restricted only to the longer physician-certified spells. Good agreement between self-reported and register data has been found $(41,42)$. We assessed SA during the past three months in each follow-up repeated at 3-month intervals, in accordance with the recommended optimum recall period of no longer than 2-3 months (41). A single item measure of LTPA may have been too rough to capture accurate information although it included the dimensions of frequency, intensity, and duration of activity. Calculation of BMI based on self-reported weight and height has been shown to identify basic relationships in epidemiological studies, even though people have a tendency to underestimate their weight and overestimate their height (43). Our measure of smoking was crude, and we were not able to calculate, for example, packyears of smoking. Therefore the clear effect of smoking on SA due to musculoskeletal pain that was found may be an underestimate.

\section{Concluding remarks}

Our study of female kitchen workers adds to the sparse literature on the course of SA behavior related to musculoskeletal pain over time. The results emphasize that in addition to multisite pain and musculoskeletal diseases, also depressive symptoms, smoking, and overweight or obesity have an important independent role in predicting the occurrence of SA due to musculoskeletal pain. Early screening and special attention to these factors seem warranted to enable prevention of their unwanted consequences on work ability.

\section{Acknowledgments}

We are grateful to the other members of the ERGO research group who were involved in the execution of the cluster randomized controlled trial, on which the current study was based. The Academy of Finland (Health Promotion Research Programme), the Finnish Work Environment Fund, the Ministry of Labor, and the Local Government Pensions Institution financially supported that core study. The Finnish Work Environment Fund has supported the current study (grant number 110355). The authors declare no competing interests.

\section{References}

1. Gimeno D, Benavides FG, Benach J, Amick BC. Distribution of sickness absence in the European Union countries. Occup Environ Med. 2004;61:867-9. http://dx.doi.org/10.1136/ oem.2003.010074 
2. Kivimäki M, Forma P, Wikström J, Halmeenmäki T, Pentti J, Elovainio M, et al. Sickness absence as a risk marker of future disability pension: the 10-town study. J Epidemiol Community Health. 2004;58:710-1. http://dx.doi. org/10.1136/jech.2003.015842.

3. OECD. Sickness, Disability and Work: Breaking the Barriers. A Synthesis of Findings across OECD Countries. http://www. oecd-ilibrary.org/social-issues-migration-health/sicknessdisability-and-work-breaking-the-barriers 9789264088856-en (accessed 25 Nov 2013). Paris: OECD; 2010.

4. Bevan S, Quadrello T, McGee R, Mahdon M, Vavrovsky A, Barham L. Fit for work? Musculoskeletal disorders in the European workforce. London: The Work Foundation; 2009.

5. Hansson T, Jensen I. Swedish Council on Technology Assessment in Health Care (SBU). Chapter 6. Sickness absence due to back and neck disorders. Scand J Public Health (Suppl). 2004;63:109-51. http://dx.doi. org/10.1080/14034950410021862.

6. Bültmann U, Rugulies R, Lund T, Christensen KB, Labriola $\mathrm{M}$, Burr H. Depressive symptoms and the risk of long-term sickness absence: a prospective study among 4747 employees in Denmark. Soc Psychiatry and Psychiatr Eepidemiol. 2006;41:875-80. http://dx.doi.org/10.1007/s00127-0060110-y.

7. Andersen LL, Mortensen OS, Hansen JV, Burr H. A prospective cohort study on severe pain as a risk factor for long-term sickness absence in blue- and white-collar workers. Occup Environ Med. 2011;68:590-2. http://dx.doi. org/10.1136/oem.2010.056259.

8. Holtermann A, Hansen JV, Burr H, Søgaard K. Prognostic factors for long-term sickness absence among employees with neck-shoulder and low-back pain. Scand J Work Environ Health. 2010;36:34-41. http://dx.doi.org/10.5271/sjweh.2883.

9. Labriola M, Lund T, Burr H. Prospective study of physical and psychosocial risk factors for sickness absence. Occup Med. 2006;56:469-74. http://dx.doi.org/10.1093/occmed/kq1058.

10. Alavinia SM, van den Berg TI, van Duivenbooden C, Elders LA, Burdorf A. Impact of work-related factors, lifestyle, and work ability on sickness absence among Dutch construction workers. Scand J Work Environ Health. 2009;35:325-33. http://dx.doi.org/10.5271/sjweh.1340.

11. Haukka E, Kaila-Kangas L, Ojajärvi A, Miranda H, Karppinen J, Viikari-Juntura E, et al. Pain in multiple sites and sickness absence trajectories: A prospective study among Finns. Pain. 2013;154:306-12. http://dx.doi.org/10.1016/j. pain.2012.11.003.

12. Van Amelsvoort LG, Spigt MG, Swaen GM, Kant I. Leisure time physical activity and sickness absenteeism; a prospective study. Occup Med. 2006;56:210-2. http://dx.doi.org/10.1093/ occmed/kqj026.

13. Grotle M, Croft P. More pain, less gain. Occup Eviron Med 2010;67:434-5. http://dx.doi.org/10.1136/oem.2009.053223.

14. Dekkers-Sánchez PM, Hoving JL, Sluiter JK, Frings-Dresen $\mathrm{MH}$. Factors associated with long-term sick leave in sicklisted employees: a systematic review. Occup Environ Med. 2008;65:153-7. http://dx.doi.org/10.1136/oem.2007.034983.
15. Oksanen T, Joensuu M, Vahtera J. Sairauspoissaolot [Sickness absences]. In: Kauppinen T, Hanhela R, Kandolin I, Karjalainen A, Kasvio A, Perkiö-Mäkelä M, et al, eds. Työ ja terveys Suomessa [Work and health in Finland in 2009] (in Finnish with english summary). Helsinki: Finnish Institute of Occupational Health; 2010.

16. Haukka E, Leino-Arjas P, Solovieva S, Ranta R, ViikariJuntura E, Riihimäki H. Co-occurrence of musculoskeletal pain among female kitchen workers. Int Arch Occup Environ Health. 2006;80:141-8. http://dx.doi.org/10.1007/s00420006-0113-8.

17. Haukka E, Leino-Arjas P, Viikari-Juntura E, Takala EP, Malmivaara A, Hopsu L, et al. A randomised controlled trial on whether a participatory ergonomics intervention could prevent musculoskeletal disorders. Occup Environ Med. 2008;65:84956. http://dx.doi.org/10.1136/oem.2007.034579.

18. Kuorinka I, Jonsson B, Kilbom A, Vinterberg H, BieringSørensen F, Andersson G, et al. Standardised Nordic questionnaires for the analysis of musculoskeletal symptoms. Appl Ergon. 1987;18:233-7. http://dx.doi.org/10.1016/00036870(87)90010-X.

19. Poutanen O, Koivisto AM, Salokangas RK. The Depression Scale (DEPS) as a case finder for depression in various subgroups of primary care patients. Eur Psychiatry. 2008;23:580-6. http:// dx.doi.org/10.1016/j.eurpsy.2008.06.007.

20. Salokangas RK, Poutanen O, Stengard E. Screening for depression in primary care. Development and validation of the Depression Scale, a screening instrument for depression. Acta Psychiatr Scand. 1995;92:10-6. http://dx.doi. org/10.1111/j.1600-0447.1995.tb09536.x.

21. Haukka E, Ojajärvi A, Takala EP, Viikari-Juntura E, LeinoArjas P. Physical workload, leisure-time physical activity, obesity and smoking as predictors of multisite musculoskeletal pain. A 2-year prospective study of kitchen workers. Occup Environ Med. 2012;69:485-92. http://dx.doi.org/10.1136/ oemed-2011-100453.

22. Elo A-L, Leppänen A, Lindström K, Ropponen T. Occupational stress questionnaire: user's instructions (reviews 19). Helsinki: Finnish Institute of Occupational Health; 1992.

23. WHO. Global Database on Body Mass Index. An interactive Surveillance Tool for Monitoring Nutrition Transition. http:// apps.who.int/bmi/index.jsp?introPage $=$ intro_3.html. (accessed 25 Nov 2013)

24. Haukka E, Pehkonen I, Leino-Arjas P, Viikari-Juntura E, Takala EP, Malmivaara A, et al. Effect of a participatory ergonomics intervention on psychosocial factors at work in a randomised controlled trial. Occup Environ Med. 2010;67:170-7. http:// dx.doi.org/10.1136/oem.2008.043786.

25. Jones BL, Nagin DS. Advances in group-based trajectory modeling and an SAS procedure for estimating them. Sociol Methods Res. 2007;35:542-71. http://dx.doi. org/10.1177/0049124106292364.

26. Nagin DS. Group-based modeling of development. Cambridge, MA: Harvard University Press; 2005.

27. Dunn KM, Jordan KP, Mancl L, Drangsholt MT, Le Resche 
L. Trajectories of pain in adolescents: a prospective cohort study. Pain. 2011;152:66-73. http://dx.doi.org/10.1016/j. pain.2010.09.006.

28. Kuijer W, Groothoff JW, Brouwer S, Geertzen JH, Dijkstra PU. Prediction of sickness absence in patients with chronic low back pain: a systematic review. J Occup Rehabil. 2006;16:43967. http://dx.doi.org/10.1007/s10926-006-9021-8.

29. Morken T, Riise T, Moen B, Hauge SH, Holien S, Langedrag A, et al. Low back pain and widespread pain predict sickness absence among industrial workers. BMC Musculoskeletal Disorders. 2003;4(1):21. http://dx.doi.org/10.1186/14712474-4-21.

30. Nordin M, Hiebert R, Pietrek M, Alexander M, Crane M, Lewis S. Association of comorbidity and outcome in episodes of nonspecific low back pain in occupational populations. J Occup Environ Medicine. 2002;44:677-84. http://dx.doi. org/10.1097/00043764-200207000-00015.

31. Alexopoulos EC, Stathi IC, Charizani F. Prevalence of musculoskeletal disorders in dentists. BMC Musculoskeletal Disorders. 2004;5:16. http://dx.doi.org/10.1186/1471-24745-16.

32. Ijzelenberg W, Burdorf A. Impact of musculoskeletal comorbidity of neck and upper extremities on healthcare utilisation and sickness absence for low back pain. Occup Environ Med. 2004;61:806-10. http://dx.doi.org/10.1136/ oem.2003.011635.

33. Bair MJ, Robinson RL, Katon W, Kroenke K. Depression and pain comorbidity: a literature review. Arch Int Med. 2003;163:2433-45. http://dx.doi.org/10.1001/ archinte.163.20.2433.

34. Demyttenaere K, Bonnewyn A, Bruffaerts R, Brugha T, De Graaf R, Alonso J. Comorbid painful physical symptoms and depression: prevalence, work loss, and help seeking. J Affect Disord 2006;92:185-93. http://dx.doi.org/10.1016/j. jad.2006.01.007.

35. Munce SE, Stansfeld SA, Blackmore ER, Stewart DE. The role of depression and chronic pain conditions in absenteeism: results from a national epidemiologic survey. J Occup Environ Medicine. 2007;49:1206-11. http://dx.doi.org/10.1097/ JOM.0b013e318157f0ba.
36. Haukka E, Leino-Arjas P, Ojajärvi A, Takala EP, ViikariJuntura E, Riihimäki H. Mental stress and psychosocial factors at work in relation to multiple-site musculoskeletal pain: A longitudinal study of kitchen workers. Eur J Pain. 2011;15:4328. http://dx.doi.org/10.1016/j.ejpain.2010.09.005.

37. Laaksonen M, Piha K, Martikainen P,Rahkonen O, Lahelma E. Health-related behaviours and sickness absence from work. Occup Environ Med. 2009;66:840-7. http://dx.doi. org/10.1136/oem.2008.039248.

38. Van den Hoven LH, Gorter KJ, Picavet HS. Measuring musculoskeletal pain by questionnaires: The manikin versus written questions. Eur J Pain. 2010;14:335-8. http://dx.doi. org/10.1016/j.ejpain.2009.06.002.

39. Streiner D, Norman G. Health measurement scales. A practical guide to their development and use. $2^{\text {nd }}$ edition. Oxford: Oxford University Press; 1995.

40. Burdorf A. The role of assessment of biomechanical exposure at the workplace in the prevention of musculoskeletal disorders. Scand J Work Environ Health. 2010;36:1-2. http:// dx.doi.org/10.5271/sjweh.2882.

41. Stapelfeldt CM, Jensen C, Andersen NT, Fleten N, Nielsen CV. Validation of sick leave measures: self-reported sick leave and sickness benefit data from a Danish national register compared to multiple workplace-registered sick leave spells in a Danish municipality. BMC Public Health. 2012;12:661. http://dx.doi. org/10.1186/1471-2458-12-661.

42. Voss M, Stark S, Alfredsson L, Vingård E, Josephson M. Comparisons of self-reported and register data on sickness absence among public employees in Sweden. Occup Environ Med. 2008;65:61-7. http://dx.doi.org/10.1136/ oem.2006.031427.

43. Spencer EA, Appleby PN, Davey GK, Key TJ. Validity of selfreported height and weight in 4808 EPIC-Oxford participants. Public Health Nutr. 2002;5:561-5. http://dx.doi.org/10.1079/ PHN2001322.

Received for publication: 19 August 2013 